\title{
Analysis of the characteristics of computer certification test suitable for higher vocational colleges
}

\author{
Dixin Song, Shufeng Jiao, Yan Xu, and Shaojie Du* \\ Binzhou Polytechnic, Binzhou 256603, Shandong, China
}

\begin{abstract}
Absrtact. With the popularization of computer application, there is a craze for computer certification in the society. Faced with a wide variety of examinations, how to choose a suitable examination is the concern of every examinee. This paper analyzes the current popular examinations from the aspects of examination organization departments, suitable people, examination methods and examination contents. It also puts forward some suggestions on the reform of computer examination.
\end{abstract}

\section{Types of computer tests}

At present, there are many types of computer examinations, among which the more popular ones are: China Computer Technology and Software Professional Qualification (Level) Examination, National Computer Rank Examination, National Computer Information High-tech Examination, National Certificate Examination of Computer Application Technology and the certification examinations of foreign IT companies. The following is an analysis one by one.

\subsection{Computer technology and software professional qualification (level) examination}

Computer Technology and Software Professional Qualification (Level) Examination (hereinafter referred to as Computer Software Qualification Examination) is the improvement and development of the original China Computer Software Professional Qualification and Level Examination. It is a national examination led by the Ministry of Human Resources and Social Security (formerly the Ministry of Personnel) and the Ministry of Industry and Information Technology (formerly the Ministry of Information Industry). Originally designed for software professionals, It was piloted in 1988 and has been tested nationwide since 1990. Since January 1, 2004, the examination has been reformed, the restrictions on registration have been lifted, and it is open to professionals and technicians from all walks of life engaged in computer application technology, software, network, information system and information service. Examinations are held twice a year. The computer software qualification examination has set up 28 professional qualifications,

\footnotetext{
* Corresponding author: ducare@126.com
} 
covering 5 professional fields. There are three levels (elementary, intermediate and advanced).

The computer software qualification examination shall be incorporated into the unified planning of the national professional qualification certificate system for professional and technical personnel. Personnel who have passed the examination and obtained the certificate show that they have the level and ability to engage in the corresponding professional posts. The employing unit may, according to the needs of the work, select and employ the corresponding professional and technical posts (technicians, assistant engineers, engineers and senior engineers) from the personnel who have obtained certificates. After the national unified computer software qualification examination, the professional and technical post qualification assessment of computer technology and software corresponding specialties and levels will no longer be carried out. So, Computer software qualification examination is not only a professional qualification examination, but also a professional and technical qualification examination.

At the same time, this kind of examination also has the level examination nature, enters oneself for an examination any rank does not need the school record, the qualifications condition, the examinee may choose the appropriate rank according to own familiar specialized situation and the level to enter oneself for an examination. Those who pass the examination will be awarded by the People's Republic of China. Ministry of Human Resources and Social Security、Ministry of Industry and Information Technology Printed computer technology and software professional qualification (level) certificate. The certificate is valid nationwide.

The computer software qualification examination has been implemented nationwide for many years, and in recent years, the scale of the examination has continued to grow. Because of its authority and seriousness, the examination has been widely recognized by all sectors of society and employers. It also promotes the development of the national information industry, especially in the software and service industries. It plays an important role in improving the quality and ability of all kinds of IT talents.

\subsection{National computer rank examination (NCRE)}

The National Computer Rank Examination (NCRE) was approved by the former State Education Commission (now Ministry of Education) approved by Examination Center of the Ministry of Education Sponsored, for the community, for Examine The national computer proficiency assessment system for examinees' computer application knowledge and skills. The grade examination is held four times a year. In March and September, all subjects at all levels will be examined, and in May and December, only the first and second levels will be examined. The provincial undertaking agencies will determine whether to open the examinations in May and December according to the actual situation. The way of examination takes the form of computer examination. There are four grades in the grade examination: the first grade mainly examines the basic knowledge and operation ability of computers, as well as the quality education of office software, graphics and image processing, and network security; The second level mainly examines the ability of computer language and programming. Candidates are required to use high-level computer languages to engage in the preparation and design of computer programs and the advanced application ability of MS Office software. Level 3 assesses the basic skills of positions related to information technology, and can participate in the development, operation and maintenance, management and service of software and hardware systems; The assessment is divided into PC technology, information management technology, network technology and database technology. Level 4 mainly examines the basic knowledge of computer 
specialty and the basic skills of analysis, design, organization and implementation of computer application projects.

Since 1994, the grade examination has adapted to the needs of the development of market economy, and the number of examinees has increased year by year. To promote learning through examinations, to promote and popularize computer knowledge to the society, and to provide a unified, objective and fair standard for the employing departments to recruit and assess staff. The courses of the grade examination are linked up with some specialized courses of the self-taught higher education examination. Those who have obtained the certificate of grade examination can be exempted from the relevant computer subjects. In addition, the grade certificate has also become the basic requirement for many units to recruit college students, and it is also an important reference standard for evaluating professional titles and promoting positions.

\subsection{National computer and information technology examination (OSTA)}

The examination is a professional examination in the field of computer and information technology organized by the Vocational Skills Appraisal Center of the Ministry of Labor and Social Security. For all kinds of college students and social workers, the focus is to assess the level of candidates'mastery of various practical computer application skills. The examination is divided into five grades. They are called junior operator, operator, senior operator, operator and senior operator respectively. The examination is mainly based on practical operation and is conducted independently according to the modules. At present, the modules for the examination are as follows:

Module Name Platform

Junior Operator Windows/Office

Office software application MS Office (intermediate), (advanced), WPS

Database application FoxBASE + 2.10, Visual FoxPro, SQL Server, Access

Computer-aided design AutoCAD, Protell

Graphics Image Processing 3D Studio, PhotoShop (Intermediate, Advanced), 3D Studio MAX, CorelDraw (Intermediate, Advanced), Illustrator

Professional typesetting Founder Book Edition, Newspaper Edition, PageMaker, Word

Internet applications Netscape, Internet Explorer, ASP (Advanced)

Computer Chinese shorthand listening and recording skills

Installation, debugging and maintenance of IBM-PC compatible computer

LAN Management Windows NT, Novell NetWare

Multimedia software production Director, Authorware (intermediate, advanced)

Application programming Visual Basic, Visual C ++, Delphi 6.0

Accounting software application UFIDA software series, Kingdee software series

Dreamweaver (intermediate, advanced), Fireworks (intermediate, advanced)

Flash (Intermediate, Advanced), FrontPage

Video editing Premiere, After Effect

The examination adopts the way of training and examination, and no longer the national unified time. The certificate shows the relevant information of the examinee, and the employer can clearly understand the actual technical level of the examinee's computer application, as a proof of the corresponding computer operation ability in other employment and job evaluation fields.

\subsection{National computer proficiency test (NIT)}

The NIT examination is sponsored by the National Examination Center of the Ministry of Education and undertaken by provincial examination institutions and systems. The purpose 
is to better promote the popularization and development of information technology in China, and to train applied information technology talents scientifically and systematically. The NIT examination focuses on the training process and adopts systematic design, modular structure, individualized teaching and standardized examination. It is closely integrated with occupation and post, has strong pertinence, and meets the needs of post training for personnel in various industries. The examination is divided into three stages: process assessment, homework design and computer examination. The trainees complete the process assessment and homework design during the training process. The computer examination is a comprehensive test of the trainees'independent operation ability and independent problem-solving ability. The examination center of the Ministry of Education unifies the proposition. The NIT exam adopts a modular structure, and the modules currently open are:

Module Name Platform

Fundamentals of Computer Applications Windows XP

Word Processing Word XP

Table Processing Excel XP

Presentation Production PowerPoint XP

Elementary and Secondary School Teachers' Information Technology Elementary and Intermediate

Web authoring Dream Weaver MX

Computer Graphics AutoCAD 2002

3D animation 3DSMAX 5.0

Animation Design Flash MX

Computer Graphic Design Photoshop 6.0

Multimedia authoring Authorware 6.0

Programming Visual Basic 6.0, Visual C + +.NET, JAVA, Delphi 6.0

Database Access 2002, Visual FoxPro 6.0, SQL Server 2000

The certificate of NIT examination can be used as the basis for exemption from examination for the course of "Computer Application Foundation" in the self-study examination and the course of "Computer Application in Management System" in the undergraduate self-study examination. Students who pass the NIT examination can also apply for the corresponding Cambridge Certificate of Information Technology (CIT) according to the relevant regulations. The CIT certificate is used in more than 40 countries and is international. Candidates can go to the Oriental Education Network http://www.eastedu.com.cn/nit/ to browse the latest news about the examination and the examination content of each module.

\subsection{Other types of computer tests}

In addition to the four influential computer tests described above, there are some other types of tests. Such as:The National Computer Proficiency Examination for Colleges and Universities, the Computer Rank Examination for Provinces (Cities), the National Computer Application Ability Examination for Professional and Technical Personnel, the Computer Application Ability Examination for Civil Servants in Provinces (Cities), and the Computer Application Abilit y Examination within Special Industries, etc.

\subsection{Certification examination of foreign IT companies}

IT Professional Technical Certification is an international professional certificate issued by Microsoft/Cisco/Novell and other internationally renowned IT companies to prove the 
acquisition of certain professional skills. At present, there are nearly 100 kinds of international certification in China.

The Microsoft Professional Certification Test (MCP) is a globally recognized certification for senior computer professionals. The MCP certificate issued by Gates is recognized in more than 90 countries around the world. The current Microsoft certifications are:

Microsoft Certified Office Professional (MOUS)

Microsoft Product Specialist Certification (MCP)

Microsoft Certified Internet Professional $(\mathrm{MCP}+\mathrm{I})$

Microsoft Certified Web Developer (MCP + SB)

Microsoft Certified Systems Engineer (MCSE)

Microsoft Certified Database Administrator (MCDBA)

Microsoft Certified Solution Developer (MCSD)

Microsoft Certified System Administrator (MCSA)

Microsoft will also introduce Application Development Expert (MCAD)

Cisco has introduced the Network Planning and Network Support Engineer Certification Program (CCCP) for its products.

Novell's Accredited Education Program is recognized as the leading network enablement program in the global IT industry. Novell qualification education programs include: Novell Certified Network Administrator (CAN), Novell Certified Network Engineer (CNE), Novell Master Certified Engineer (Master CNE), etc.

The certification exams of these world-renowned IT companies are completed through computer education and examination certification services such as Prometric and ATA. Prometric offers certification exams from more than 60 companies worldwide. Including Microsoft, Oracle, Cisco, Sun, HP, Lucent, BEA, IBM/Lotus, Linux, Intel, Baan, CA, Novell, SCO, Compaq, UNIX, Adobe, Nortel, Avid, Linux, CIW, etc.

The certification of foreign IT companies is a stepping stone to enter the company's related enterprises for employment, which means a good working environment and favorable treatment. Of course, the cost of attending certification training and examinations is also relatively high.

\section{Some suggestions on the reform of computer examination}

\subsection{The content of the examination should be updated in a timely manner}

With the continuous development of computer technology, the application field has become wider and wider, and there are more and more branches of technology. The expansibility and ease of use of technology have become the characteristics of computer development. With this change, some popular computer examinations abroad have gradually changed their direction, such as the requirement for the primary computer certificate has changed from theoretical understanding to technical application. From the assessment of knowledge mastery to the evaluation of ability. At present, the content of computer examination in our country is relatively old, and the content of examination is out of touch with practical application. In order to make the computer examination keep pace with the times, we should constantly revise the examination syllabus and update the examination content. The renewal period should not exceed two years[5]. 


\subsection{A variety of computer examinations should be combined.}

The basic knowledge of computers is universal. At present, these computer tests, except for the proficiency test, belong to the popularization stage, and there is little difference. It is beneficial to the development of the whole computer examination work to merge this kind of examination. Such as: The computer proficiency examination of the provinces (cities) of the national colleges and universities and the computer grade examination of the provinces (cities) can be merged into the national computer grade examination. The National Computer Application Ability Examination for Professional and Technical Personnel and the Provincial (Municipal) Civil Servant Computer Application Ability Examination can be merged into the NIT Examination. If the merger cannot be achieved, the validity of the certificate should also be mutually confirmed. This can reduce the burden of candidates.

\subsection{Training and examination shall be conducted separately.}

The separation of teaching and examination, the separation of training base and examination base, and the establishment of effective restriction mechanism can promote the standardization of computer training and examination, and avoid the phenomenon that certificates can be obtained as long as they participate in training. The implementation of paperless examination, the use of computer questions, answers, papers and automatic scoring, to ensure the fairness and accuracy of the examination.

\section{Conclusion}

Today, when "not knowing computers" has been included in the definition of illiteracy, the computer examination examines the examinees.

The level of computer knowledge and skills provides a strong proof for qualified personnel in job selection, employment and promotion. It has played an important role in promoting the popularization and application of computer knowledge.

\section{References}

1. Software Proficiency Test Network http://www.exam100.com/

2. National Computer Rank Examination Network http://www.ncre.cn/

3. National Computer Information High-tech Examination Network http://www.citt.org.cn/

4. Oriental Education Network http://www.eastedu.com.cn/nit/

5. Luo Xiaopei. On computer examination and computer education. New Computers, 2003, (04): 285 